\title{
OS SEGUIDORES DE OSÍRIS \\ O Pós-Vida nas Estelas Egípcias do Museu Nacional
}

\author{
WORSHIPPING OSIRIS \\ Afterlife Conceptions in the Egyptian stelae of the National \\ Museum of Rio de Janeiro
}

\author{
Antonio Brancaglion Junior ${ }^{1}$ \\ inpw@mn.ufrj.br
}

\section{RESUMO}

Talvez nenhuma outra cultura tenha criado um conjunto de crenças e práticas funerárias tão complexo e diversificado quanto os egípcios antigos. Em um panteão repleto de divindades funerárias, Osíris se destaca como a própria essência e princípio explicativo da morte e do pós-vida. Entre as práticas funerárias destaca-se a peregrinação até a cidade de Abidos, local de devoção a Osíris, onde eram depositadas estelas em honra ao deus e aos mortos. O Museu Nacional do Rio de Janeiro possui uma grande coleção destas estelas, testemunhos da piedade pessoal e da esperança em uma vida postmortem sob as graças de Osíris.

Palavras-chave: Osíris, práticas funerárias, estelas funerárias, Museu Nacional.

\footnotetext{
${ }^{1}$ Museu Nacional do Rio de Janeiro, MN-UFRJ.
} 


\begin{abstract}
Like no other culture, the ancient Egyptians are known for having created a whole set of complex funerary beliefs and practices. Amongst several deities, the Egyptians attributed a prominent role to Osiris, as the very essence and explanatory principle of their afterlife conceptions. The journey to Abydos, sacred city associated with Osiris, was an important part of the devotion to this god. There, the Egyptians left votive stelae dedicated to Osiris and the deceased. The National Museum of Rio de Janeiro houses a large collection of Egyptian stelae, which are sources for the study of the Egyptians' personal piety and belief in an afterlife associated with Osiris.
\end{abstract}

Keywords: Osiris, funerary practices, funerary stelae, the National Museum of Rio de Janeiro.

\title{
ANTECEDENTES
}

O Museu Nacional da Universidade Federal do Rio de Janeiro possui a mais importante coleção egípcia da América do Sul. Composta por objetos únicos no Brasil sendo a mais antiga coleção egípcia em um museu das Américas.

Esta coleção foi em grande parte adquirida por Dom Pedro I que a comprou para o Museu Real, em 1826, de um comerciante italiano chamado Nicolau Fiengo. Este comerciante vindo de Marselha declarou que os objetos foram recolhidos pelo famoso negociante de antiguidades egípcias Giovanni Battista Belzoni (17781823). Belzoni e outros saqueadores trabalhavam para o diplomata Bernardino Drovetti (1776-1852) fornecedor dos grandes museus europeus.

O interesse pelo Egito Faraônico foi continuado por D. Pedro II, um apaixonado pela cultura oriental. Além das aquisições feitas pelos imperadores a coleção 
egípcia foi enriquecida, durante o início do século XX, por algumas doações de particulares.

A quase totalidade da coleção é formada por objetos funerários provenientes da necrópole tebana localizada na margem esquerda do Nilo na atual Luxor.

Uma parte importante deste acervo é formado por estelas em sua maioria funerárias e votivas, datadas do Médio Império até o Período Romano.

O objetivo deste artigo é mostrar a relação dos egípcios antigos com seus mortos por intermédio de uma categoria específica de objetos, as estelas votivas. Além de mostrar como é feito o trabalho da egiptologia em estudos pontuais realizados no acervo do Museu Nacional do Rio de Janeiro.

\section{AS ESTELAS}

O Museu Nacional possui 49 estelas de diferentes períodos. Em sua maioria feitas em calcário com figuras e textos incisos e originalmente coloridas.

As estelas são lajes em rocha ou madeira e, mais raramente, em faiança, que poderiam conter cenas e inscrições referentes a decretos e registros históricos de realizações reais, demarcações de fronteira, hinos e preces a divindades. Contudo, em sua maior parte tinha uma função funerária sendo o ponto focal o culto ao 
morto e, portanto, colocada sempre em um local de livre acesso na capela funerária.

As estelas não reais morfologicamente apresentam três tipos:

1 - Com topo arredondado, possivelmente uma alusão aos tetos abobadados das capelas memoriais;

2 - As retangulares, uma reprodução em escala reduzida das paredes da capela;

3 - A "porta-falsa" reproduzindo elementos arquitetônicos de uma porta.

Os antigos egípcios tinham pelo menos duas palavras para designar as estelas, uma ligada a ideia de "perdurar", "permanecer" e outra "proclamar", “declarar". No caso das estelas votivas também usavam a palavra "anunciar".

Desde o Antigo Império as estelas são destinadas a assegurar a perpetuidade das oferendas funerárias, pela representação dos mortos diante de uma mesa de oferendas e pela inscrição de invocações de proscinemas. Elas frequentemente representam vários membros de uma mesma família, sejam como beneficiários das oferendas sejam como oficiantes dos rituais, pois o culto aos mortos era executado pelos parentes e seus descendentes ou por sacerdotes contratados que se apresentavam como filho do morto. 
No decorrer do Antigo Império surge a estela "porta-falsa", chamada "a boca da casa", isto é, o túmulo.

Feita em rocha e, mais raramente, em madeira ela reproduz uma porta com a imagem do morto diante de uma mesa de oferendas e um texto com as invocações de oferendas. Era localizada, normalmente, sobre o poço ligado à câmara funerária do lado oeste da tumba. Esta porta permitiria ao morto comunicar-se com os vivos e ter acesso às oferendas que eram depositadas diante dela.

Pouco a pouco, a partir do início do Novo Império, a estela toma a sua forma "clássica" com o topo arredondado, dividida geralmente em dois registros e com um terceiro registro só com texto. $\mathrm{O}$ registro superior mostra, frequentemente, o morto algumas vezes acompanhado por sua esposa diante de divindades. Quase invariavelmente os indivíduos mais importantes, divindades, o rei ou o morto estão no lado esquerdo, muitas vezes sentados em tronos ou cadeiras. No registro inferior, o morto e sua esposa segurando flores de lótus, sentados diante de uma mesa de oferendas. Diante destes seus familiares dispostos como participantes de um ritual de oferenda prestam homenagens. É nesta época, também, que aparecem as estelas com representações do morto diante de divindades.

Convém, entretanto, não se prender a fórmulas esquematizadas com respeito aos temas tratados nas estelas. Na realidade as formas e o conteúdo variam conforme a época e os destinatários. 
De forma simples e objetiva, já que não é a minha intenção fazer uma revisão tipológica, podemos dizer que estelas "porta-falsa" se referem a um dispositivo arquitetônico colocado nos túmulos do Dinástico Inicial e principalmente do Antigo Império.

Estelas funerárias normalmente eram depositadas nas capelas das tumbas trazendo uma representação do morto e a fórmula de oferendas. As estelas funerárias podem trazer também, a partir do Novo Império imagens de divindades e da vida pós-morte.

Estelas votivas são principalmente datadas do Médio e Novo Império ofertadas por particulares em templos, capelas divinas, santuários e mesmo em residências.

Com frequência mostram uma adoração individual a uma divindade e algumas delas não trazem o proscinema ou fórmula de oferendas.

Algumas estelas votivas podem de fato ser definidas como comemorativas ou memoriais, principalmente aquelas depositadas em Abidos como veremos.

No início do século XX o interesse maior estava focado na formulação de uma tipologia e na datação das estelas porta-falsa do Antigo Império e nas estelas do Médio Império. 
As estelas do Novo Império eram consideradas (textos e imagens) como uma continuação daquelas do Médio Império, com a mesma função sendo as inovações decorrentes de variações estilísticas.

Questões como localização, estrutura e funcionalidade eram secundárias diante da tipologia e da categorização.

O grande número de estelas do Médio Império, principalmente aquelas provenientes de Abidos, resultou em inúmeros estudos de iconografia e dos seus textos com ênfase na datação e pouco sobre o contexto arqueológico ou social destas estelas.

As estelas do Novo Império foram sempre divididas entre funerárias ou votivas, estas últimas consideradas como expressão do fenômeno conhecido como “piedade pessoal”, isto é, representações simbólicas de um relacionamento pessoal com uma divindade, expressão de um conceito existente antes do Novo Império, mas sem uma articulação adequada ou sistemática, sendo a expressão máxima presente nas estelas de Deir el-Medina.

Durante o Antigo Império o status social e religioso estavam conectados, mas a partir do Novo Império o acesso as divindades tornou-se um fenômeno separado daquele social do indivíduo. Os particulares passaram a ter acesso ao mundo divino, antes privilégio exclusivo das elites. 
Sem dúvida, monumentos com inscrições estão intimamente ligados ao poder e refletem a ordem das relações sociais dentro de um conjunto de convenções estritamente controladas.

As convenções e regras contidas nos textos (títulos e fórmulas) e nas imagens das estelas do Médio e Novo Império são em si uma expressão da estrutura social e do decoro. Além disso as estelas, funerárias e votivas são a materialização da auto representação dos indivíduos, de como estes querem ser lembrados pela sociedade, sua genealogia e sua prosopografia.

A razão mais óbvia para a criação de um monumento privado (votivo ou funerário) é o temor do esquecimento, entendido pelos antigos egípcios como uma segunda morte, capaz de lançar o morto a não existência e ao fim absoluto.

Os egípcios antigos dividiam os mortos em duas categorias: Os "glorificados", aqueles transfigurados pelos ritos e pela mumificação, tornando-se bemaventurados desfrutando de uma vida póstuma semelhante a um deus (Osíris). E os "malditos", aqueles que não eram honrados pelos rituais nem lembrados pelos vivos, sem uma existência pós vida eram aniquilados e identificados com os inimigos dos deuses. 
No Egito antigo o sucesso das (auto)biografias revela a preocupação com a memória do indivíduo, seus atos, sua carreira e sua vida bem-sucedida.

Embora apresentados conforme as normas sociais padronizadas os monumentos particulares apresentam uma individualidade. A análise das convenções (decoro), as escolhas na iconografia, nas fórmulas e nos títulos nos revelam aspectos pessoais fundamentais para a compreensão da sociedade egípcia para além da aparente homogeneidade apresentada nos museus e nos livros de história e que pouco refletem a complexidade da civilização egípcia.

Um dos grandes valores da coleção egípcia do Museu Nacional está justamente no fato de que grande parte do acervo é formado por objetos provenientes não da elite, mas de servidores, em sua maioria sacerdotes tebanos do que poderíamos chamar de uma classe intermediária entre os trabalhadores e camponeses e a elite palaciana.

No estudo das estelas do Museu Nacional a técnica empregada é aquela há muito consagrada pela arqueologia do Mundo Antigo, a Epigrafia.

A epigrafia é uma área de grande interesse da Egiptologia particularmente no estudo das variações dos sinais hieroglíficos.

Talvez o primeiro trabalho epigráfico (nomine digna) feito no Egito tenha sido aquele realizado por Karl Richard Lepsius em 1875, reproduzindo e registrando os 
relevos e inscrições dos monumentos publicando mais tarde no Denkmäler aus Aegypten und Aethiopien, criando o primeiro corpus padronizado com reproduções fiéis e proporcionais das imagens e dos textos apresentados de forma cronológica e geográfica.

O objetivo da epigrafia aplicado ao estudo de coleções egípcias não é a simples reprodução dos objetos em fac-símiles, mas o uso das inscrições hieroglíficas e das cenas como forma de datação, interpretação e estabelecimento da procedência do material arqueológico. Particularmente importante no estudo de coleções em museus, a epigrafia é praticamente o único método de obtenção de informações que permite recompor o contexto arqueológico dos objetos cuja procedência é desconhecida, como os do Museu Nacional.

O exame paleográfico do desenvolvimento e das características dos sinais e das imagens permite apresentar considerações sobre a cronologia, a origem e a função do objeto buscando recriar o seu contexto.

Como um exemplo deste processo epigráfico podemos citar um objeto catalogado inicialmente como sendo uma estela funerária com a imagem em alto relevo de um personagem cuja inscrição diz chamar-se Sehetepibre (Figura 1). 


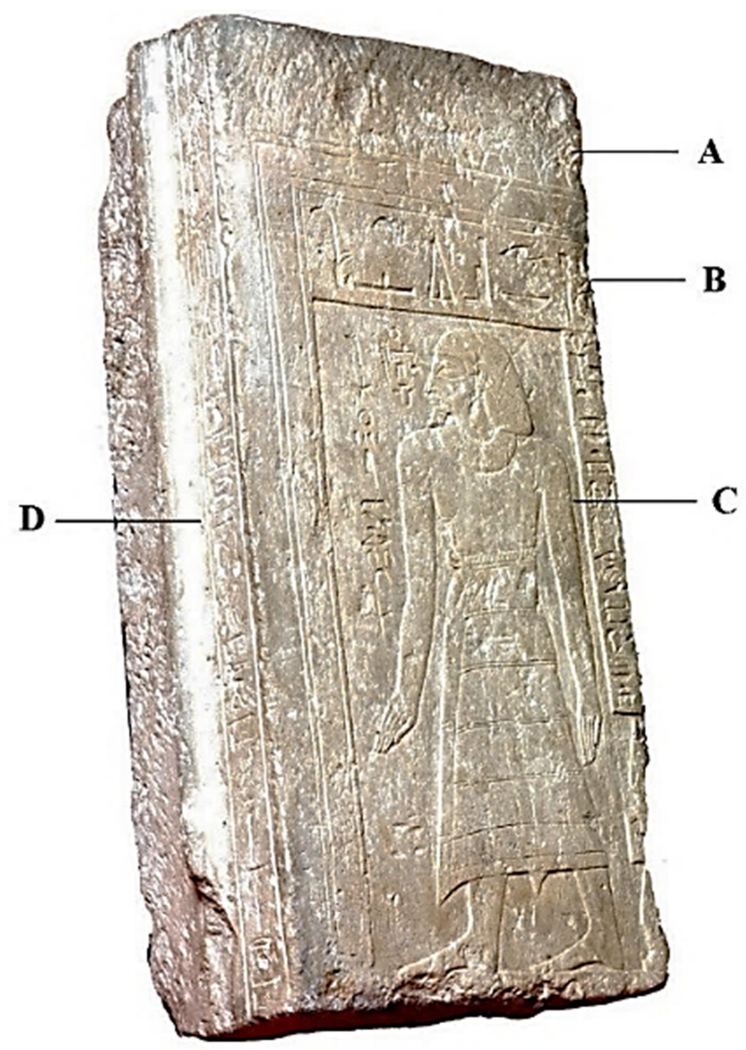

Figura 1. Estela de Sehetepibre, A. Friso de kheker; B. Fórmula de Oferendas; C. Imagem de Sehetepibre; D. Borda, com coluna de hieróglifos (foto do autor)

Uma análise mais cuidadosa mostra que na verdade trata-se de um fragmento arquitetônico, parte de uma capela funerária ou votiva.

Sehetepibre é um nome frequente durante o Médio Império, principalmente a partir da XII dinastia (c. 1991 a.C.) por se tratar de um dos nomes do faraó Amenemhat I. 
O título que antecede seu nome, inciso a sua frente pode ser traduzido como "Chefe dos Dez do Alto Egito". Um título surgido no Antigo Império, mas que se tornou comum durante a XII e XIII dinastias (1991 a 1650 a.C.).

A função designada por este título ainda permanece desconhecida, mas estava conectada diretamente com o vizir e a administração de assuntos legais do palácio, provavelmente Sehetepibre representasse o vizir em diferentes tarefas por todo o Alto Egito.

Logo acima da imagem de Sehetepibre temos uma linha de hieróglifos que se destaca pela grande dimensão dos sinais (Figura 1B). Nela se lê a tradicional "fórmula de oferendas", uma inscrição memorial e comemorativa encontrada em praticamente todas as categorias de objetos funerários, desde o Antigo Império até o Período Romano.

Ela possui duas funções principais:

Oficial - na qual o status do morto é declarado como sendo reconhecido pelos serviços prestados ao rei.

Pessoal - na qual o morto é reconhecido por seus familiares e pela sociedade como merecedor de um culto por seu comportamento ético e moral. 
Por meio dela o morto está capacitado a compartilhar das oferendas feitas pelo faraó às divindades nos templos. Ela conecta o morto com a esfera mais importante do culto que é aquela da relação entre o monarca divino com as divindades.Nela lemos:

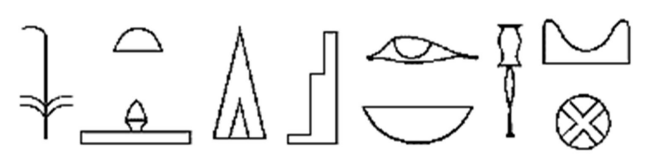

"Oferenda que o rei faz (para) Osíris, Senhor de Abdju (Abidos)".

A análise da isografia da fórmula de oferendas mostra que ela segue a tradição menfita, surgida na IV dinastia (c. 2570 a.C.), conforme a Figura 2 A.

Com a fragmentação do poder central na XIII dinastia, no reinado de Sobkhotep VI (c. 1730 a.C.), surge uma nova maneira de escrever esta fórmula conhecida como tradição tebana (Figura 2B). Isto indica que este fragmento é anterior a esta data.

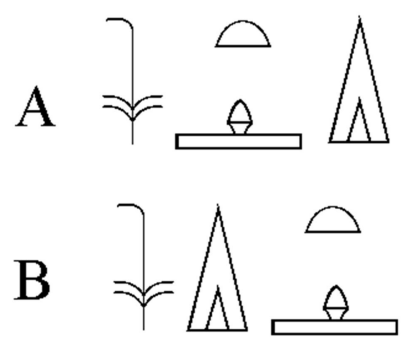

Figura 2. Isografia da Fórmula de oferendas 
Complementando a análise do texto temos a análise iconográfica da imagem de Sehetepibre (Figura 1C).

As variações no estilo, nas proporções e os elementos que compõem a cena como vestimenta, colar e toucado são fundamentais para o aprimoramento da datação, localização e identificação do objeto. O longo saiote usado por Sehetepibre é bastante distinto aparecendo em monumentos funerários (estelas e tumbas) datadas do reinado de Amenemhat IV (Figura 3). Exemplos deste tipo de saiote aparecem em estelas em outros museus datadas da XIII dinastia (c. $1750 \quad$ a.C.).

Característicos dos homens da elite com cargos administrativos elevados.

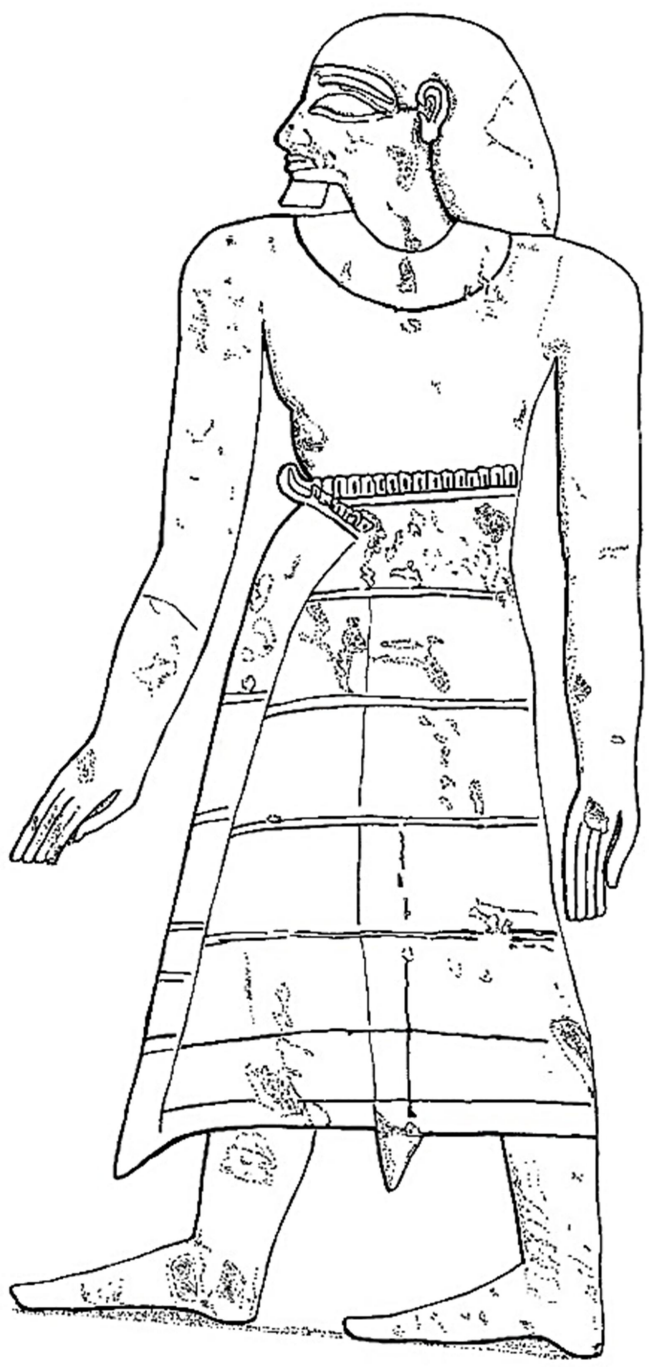

Figura 3. Figura de Sehetepibre (desenho do autor) 
A posição dos braços e das mãos são características das imagens em relevo e estátuas. Surgido na XII dinastia este gesto representa a submissão do devoto diante de uma divindade. Surgida primeiro nas representações civis, será mais tarde adotada pelos faraós sendo Senusret III (c. 1878-1841? a.C.) o primeiro a adota-la.

No alto do fragmento temos um friso de kheker, um elemento decorativo sempre encontrado na parte superior das paredes das tumbas e capelas o que indica que esta imagem ficaria na parte mais alta da parede (Figura 1A).

$\mathrm{Na}$ lateral esquerda do fragmento (Figura 1D) temos uma borda com uma coluna de hieróglifos incisos, os sinais estão voltados para a direita, em direção à imagem de Sehetepibre que está voltada para esquerda, isto indica a parede esquerda já que a figura ficaria voltada para a entrada da capela.

Nesta coluna da borda lemos:

Ifinm

“Aclamação a Osíris Khenty-Imentyw prosternar-se para Unnefer na Grande Procissão por Aquele que é o Conhecido do Rei verdadeiramente [...]" 
A "Grande Procissão" era o principal momento panegírico das cerimônias anuais realizadas em Abidos, um cortejo em honra à forma local do deus Osíris.

A expressão "prosternar-me", literalmente "beijar o chão", significaria que o devoto participou realmente deste momento solene e ao colocar esta inscrição em uma capela votiva desejava que a sua participação fosse eterna, bem como seria um sinal para todos de seu status elevado.

Portanto, por meio da análise epigráfica aplicada ao fragmento podemos obter informações que nos permitem recompor o contexto arqueológico permitindo chegar à conclusão que ele se trata do topo do umbral esquerdo de uma capela votiva que Sehetepibre mandou construir em Abidos, provavelmente na chamada zona votiva onde foram erguidas as capelas da XII a XIII dinastia.

O estudo do relevo de Sehetepibre nos fornece também a possibilidade de aplicação de outra técnica muito usada na Egiptologia, a Anastilose, isto é, buscar em outros museus eventuais objetos pertencentes a sua capela memorial, ou sua tumba e assim complementar as informações sobre sua vida e sobre o período em que viveu.

O mesmo tipo de análise está sendo realizado nas outras estelas e fragmentos de monumentos da coleção do Museu Nacional. 
No século XIX e início do XX era comum a remoção das cores das estelas e estátuas egípcias. Os objetos eram lavados para expor melhor a rocha e as formas, uma prática inspirada pelo "gosto clássico" das obras gregas e romanas.

A utilização de microscópios digitais no estudo das estelas egípcias possibilitou não só o registro de detalhes paleográficos como também auxiliou na reconstituição das cores originais ao permitir o registro fotográfico dos resíduos de pigmentos.

Um exemplo deste processo ocorreu no estudo da estela de Renefankh e seus familiares (Figura 4). Feita em calcário, apresentando somente alguns traços de tinta amarela no topo, revelou nas macrofotografias traços de tinta amarela na superfície da estela e azul na parte interna dos hieróglifos e figuras o que permitiu a sua reconstituição (Figuras 5 e 6).

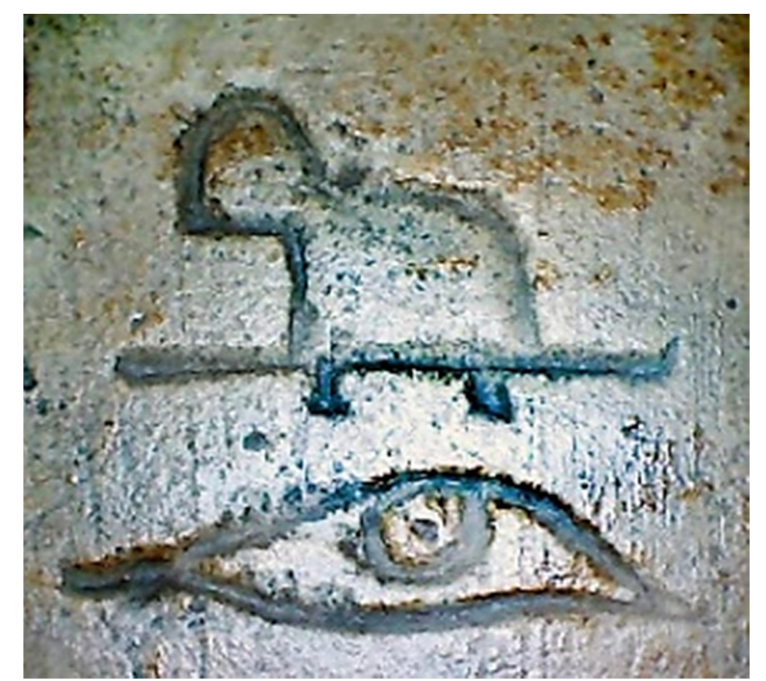

Figura 5. Macrofotografia dos hieróglifos que formam o nome Osíris. (foto do autor) 


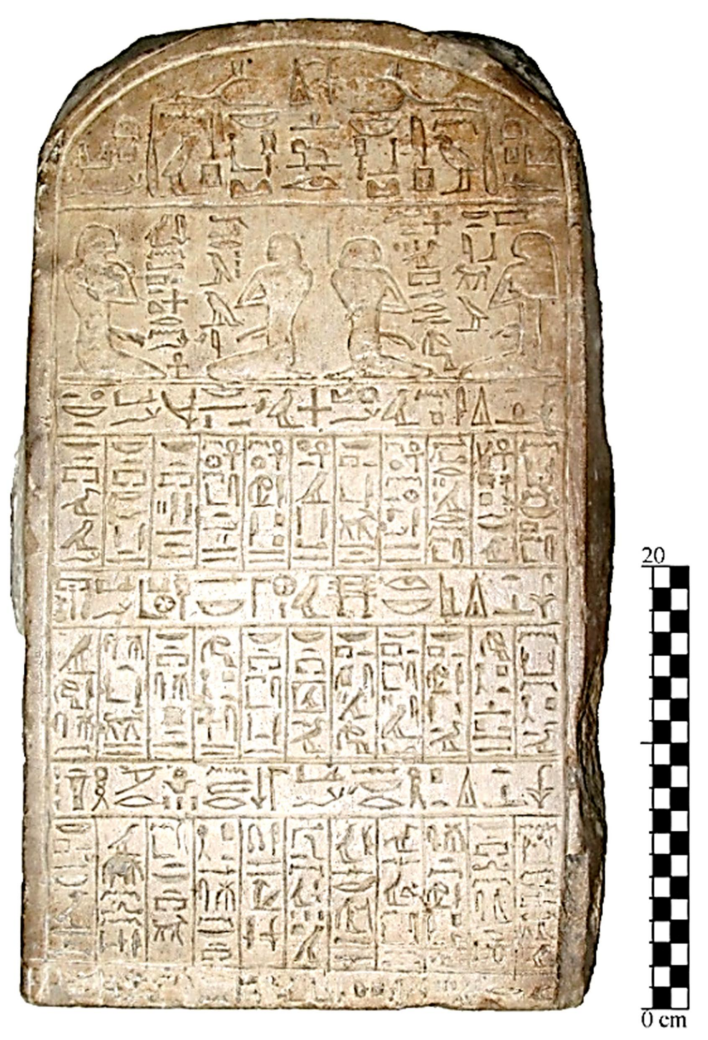

Figura 4. Estela de Renefankh (foto do autor)

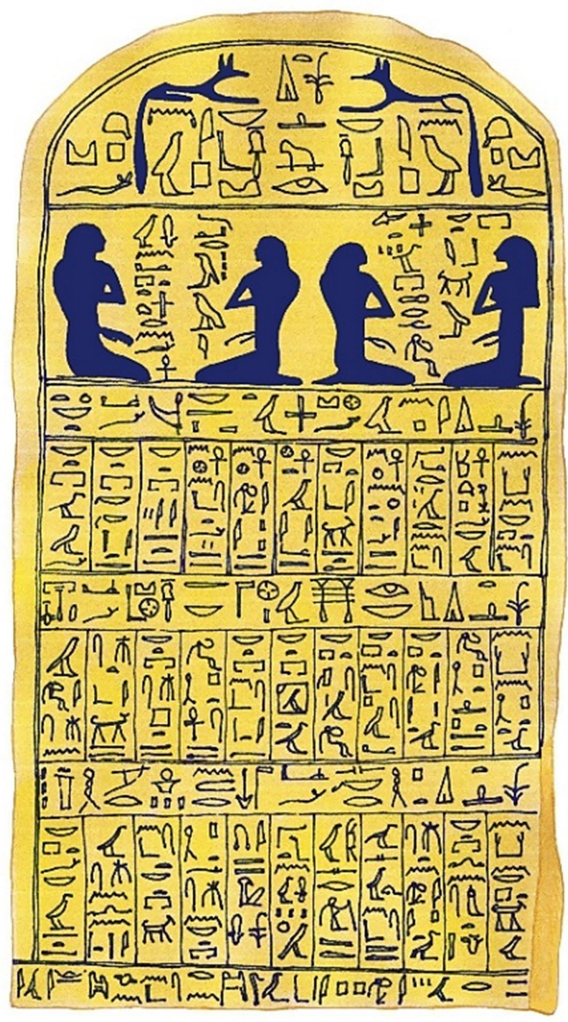

Figura 6. Reconstituição da Estela de Renefankh

\section{O MÉDIO IMPÉRIO E A COLEÇÃO DO MUSEU NACIONAL}

Além do relevo da capela de Sehetepibre e da estela de Renefankh, outras 20 estelas da coleção do Museu Nacional são datadas do Médio Império entre a XII e XIII dinastias (c. 1991 a 1730 a.C.). 
O Médio Império tem início após a divisão do poder entre governantes provinciais - muitos deles rivais do faraó - durante o Primeiro Período Intermediário, o Egito foi reunificado no XXI século a.C. durante a XI dinastia, pelo rei Mentuhotep II, originário de Tebas.

Durante o Antigo Império, Tebas, havia sido um centro provincial de menor importância, mas durante a XI dinastia, tornou-se um grande centro religioso principalmente o templo Karnak cujo deus local Amun ganhou uma projeção nacional.

O restabelecimento do poder central é (re)estruturado segundo um modelo semelhante ao do Antigo Império, com um vizirato representando o poder máximo da administração civil.

Os centros administrativos locais passam ao controle de um governador (nomarca) indicado pelo soberano. Sob o reinado de Senusret III na XII dinastia (c. 1878 a.C.) ocorre a maior reorganização do Estado, com o estabelecimento de três "departamentos administrativos" para o Alto, Médio e Baixo Egito além da criação de um departamento responsável pela organização dos trabalhos e execução dos projetos do Estado.

A irrigação também foi incrementada com a construção de diques e canais, aumentando as terras férteis principalmente na região do Fayum, para onde a 
capital administrativa foi transferida na XII dinastia. Foram construídas fortalezas próximas à segunda catarata do Nilo na Baixa Núbia a mais importante foi um conjunto de três fortalezas chamadas Semna estabelecidas por Senusret I.

O Médio Império é o período de florescimento da literatura e da adoção de uma forma culta para a escrita hieroglífica (egípcio médio). É também o tempo de mudanças ideológicas e de desenvolvimento das crenças e práticas funerárias principalmente ligadas a Osíris, um rei divino que derrota a morte renascendo em uma nova existência póstuma, dando a esperança em um pós-vida a todos os mortais, o que antes era exclusividade dos faraós e sua família. É neste período que a cidade de Abidos, o principal centro de culto a Osíris no Alto Egito ganha um destaque nacional.

Os predecessores de Menthotep II já haviam dado início a necrópole tebana mandando escavar hipogeos nas encostas de el-Tarif, mas foi com a construção de seu templo memorial em Deir el-Bahari que Mentuhotep II inspirou as futuras gerações a construírem as suas tumbas e complexos funerários em Tebas Ocidental.

\section{ABIDOS E A COLEÇÃO DO MUSEU NACIONAL}


Como vimos anteriormente Abidos foi o local de origem do relevo da capela de Sehetepibre, da estela de Renefankh além de outras 20 estelas datadas do Médio Império, 22 do Novo Império (XVIII a XX dinastias) e 6 da Baixa Época, todas estelas da não elite relacionadas ao culto de Osíris e a perpetuação da memória familiar além-túmulo.

A cidade de Abidos foi o principal centro de culto ao deus Osíris, a cerca de 100 $\mathrm{km}$ ao norte de Tebas, este sítio foi ocupado desde o Período Amratense (Naqada I c. 4200 a.C.) e o local da primeira necrópole real Proto-dinástica (I e II dinastias c. 2920 a 2649 a.C.)

Abidos tornou-se um importante centro religioso nacional desde o início da XI dinastia quando o faraó Antef II (c. 2123 a 2074 a.C.) tornou-a oficialmente a cidade santa sede do culto a Osíris.

A partir da XII dinastia passou a ser um local de peregrinação de pessoas de todo o Egito. Abidos torna-se o primeiro local conhecido onde uma peregrinação em massa ocorria todos os anos no Egito.

Com a popularização da crença no pós-vida osiríaco ocorrido durante o Médio Império surgem as estelas e as capelas votivas particulares como as do Museu Nacional. 
As estelas eram depositadas em capelas memoriais chamadas mahat cujo termo mais apropriado seria capela votiva ou capela-cenotáfio (Figura 7). Estas capelas eram individuais ou familiares, o próprio deus Osíris teria uma em um local de Abidos chamado Peker.

Eram verdadeiros templos em miniatura, que abrigavam imagens dos devotos, acompanhado por seus familiares como vemos nas estelas e fragmentos de capelas do Museu Nacional. A presença dos familiares parece ser uma característica das estelas abidianas, o que talvez se deva a forte presença da família no mito de Osíris.

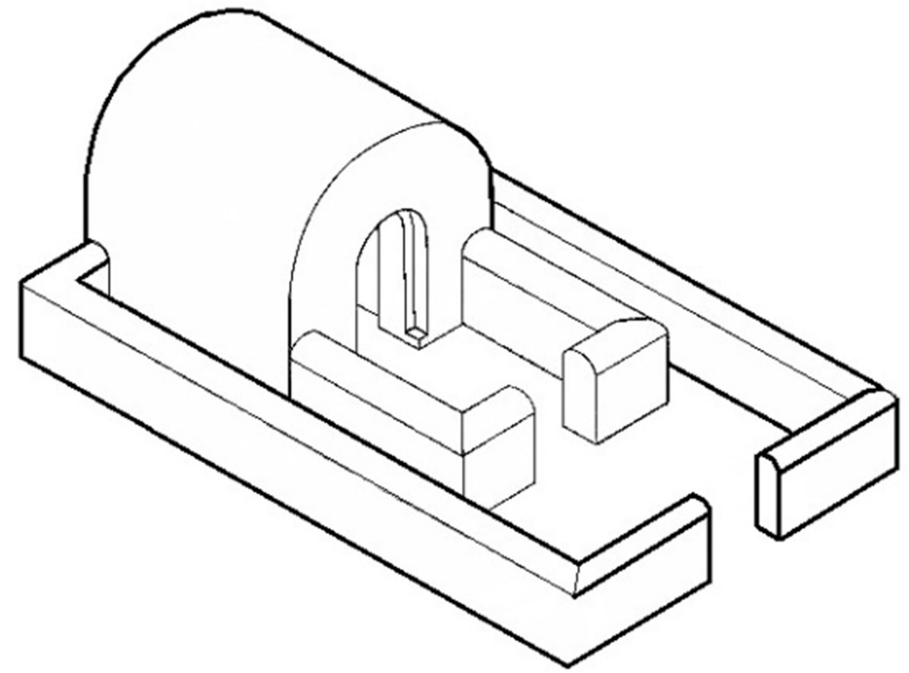

Figura 7. Reconstituição de uma capela votiva de Abidos durante o Médio Império. (desenho do autor a partir de O'Connor Abydos 47) 
Estas capelas e estelas eram uma maneira dos devotos participarem eternamente do festival que celebrava a morte e ressureição de Osíris. Elas eram dispostas ao longo da via processional, ao longo de um wadi, que ligava o templo de Osíris a Umm el-Qa'ab (Figura 8).

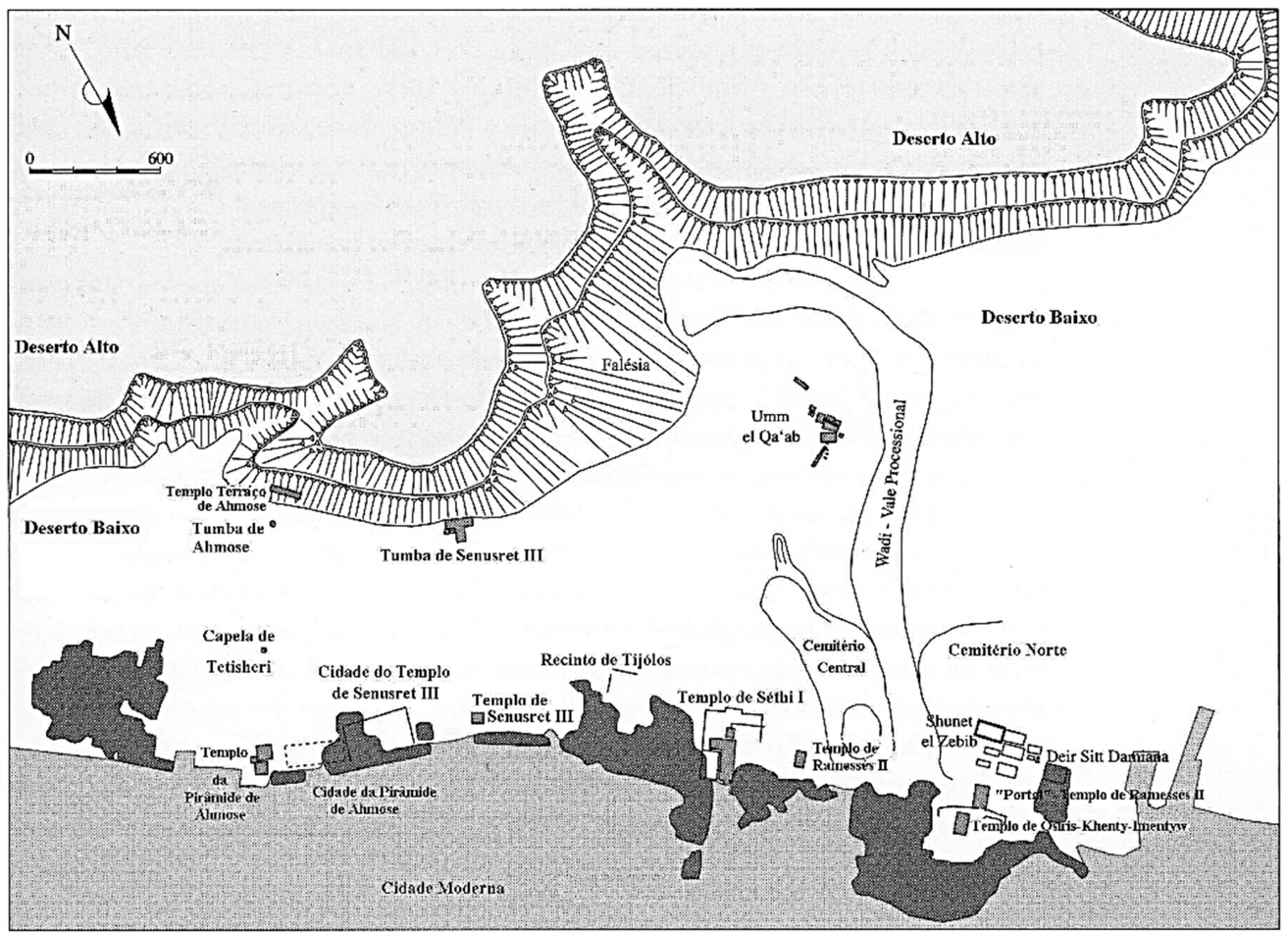

Figura 8. Monumentos de Abidos (mapa do autor a partir de O’Connor Abydos 3). 
Este caminho, chamado de "Terraço do Grande Deus", era percorrido pela procissão durante o festival anual, uma referência metafórica aos mistérios de Osíris onde relembravam a vida, a morte e a ressurreição do deus.

O local era considerado tão sagrado que o controle do acesso físico ao wadi processional aparece citado em uma estela do Museu do Cairo onde um decreto do reinado de Neferhotep I determina que uma pessoa encontrada dentro da área protegida fora do período do festival seria queimada viva.

Algumas das estelas depositadas no "Terraço do Grande Deus" possuem uma inscrição atualmente denominada "fórmula abidiana" semelhante a do relevo de Sehetepibre (Figura 1D). A fórmula "padrão" é:

"prosternar-se para Khenty-Imentyw na Grande Procissão vendo as belezas (de) Wep-wawet na Primeira Procissão (nome do morto)"

Como vimos no relevo do Museu Nacional, esta frase pode ser interpretada como tendo o ofertante da estela testemunhado à procissão sendo seu desejo participar eternamente destes rituais após a sua morte.

Nas estelas normalmente temos o nome e títulos do ofertante acompanhado por uma lista de seus familiares e mesmo de seus empregados e subordinados. Com frequência um homem de status elevado apresentava outros, mesmo não familiares, como beneficiários junto com ele na estela. 
Existem ainda aquelas onde um grupo profissional (artistas, soldados etc.) dedicava uma estela em benefício de seu patrão. Ou artesãos que possivelmente reduziriam os custos de confecção de uma estela se o seu nome fosse incluído, uma espécie de cotização para benefício póstumo mútuo.

Um exemplo destas estelas votivas associadas a uma confraria é aquela de Renefankh (Figura 4). Nela encontramos vários indivíduos com títulos ligados a confecção de sandálias de couro o principal deles é "Supervisor da Corporação dos Fabricantes de Sandálias".

A inclusão de uma pessoa de status elevado (status abidiano) talvez tenha sido a única maneira de uma pessoa fora do meio social adequado alcançar este meio divino, ou seja, uma pessoa socialmente mais elevada permitiria o acesso de pessoas menos favorecidas, como colegas de ofício e familiares.

O festival anual era o momento da colocação de novas estelas, de visitar as capelas e é claro presenciar a procissão com a imagem do deus.

O festival desenvolvia-se em dois momentos diferentes: no primeiro - público - a imagem do deus era transportada pela via processional que saía do lado oeste do templo. A segunda etapa - secreta - ocorria no deserto no interior da necrópole onde os ritos dos mistérios da paixão de Osíris eram encenados pelos sacerdotes. 
A função deste festival era celebrar o sepultamento e o renascimento de Osíris como uma promessa de uma vida póstuma acessível a todos os mortais.

O festival compreendia cinco partes principais:

1. Procissão guiada pelo deus Wep-wawet que culminava com o combate contra os inimigos de Osíris. Representava a vitória da realeza repelindo as forças do Caos e da Desordem, possivelmente refletia a ameaça da desestabilidade com a morte dos antigos reis divinos como Osíris.

2. A grande procissão do deus Osíris. Representava a procissão funerária do próprio deus, como um rei morto, quando ele foi preparado e equipado para o sepultamento. Osíris aparece em sua forma de Khenty-Imentyw, conduzido do templo através do cemitério. É a este aspecto do deus Osíris que são endereçadas as preces de oferendas de algumas das estelas do Museu Nacional.

3. A jornada do deus para Peker. O deus era transportado em uma grande barca cerimonial pelo deserto até a sua suposta tumba, provavelmente a tumba do rei Djer da I dinastia (Umm el-Qa'ab).

4. Uma noite de vigília na qual o deus era rejuvenescido como Unnefer (Wnn-nfr) "Aquele que está em Boas Condições". Era a noite da festividade Haker e o assassinato dos inimigos de Osíris em Nedyet (ndi.t), o local mitológico de sua 
morte. Era a parte mais reservada e secreta dos mistérios. No momento final Osíris recebia a "Coroa da Justificação" e era transfigurado em um ser "Glorioso".

5. A jornada de retorno ao templo sob a aclamação geral dos fiéis. A imagem de Osíris reentrava no templo pela via processional.

Desde o início do século XIX muitas das estelas abidianas foram comercializadas por mercadores de antiguidades, incluindo as do Museu Nacional, estas escavações clandestinas resultaram na perda do contexto da maioria das estelas de Abidos.

Outras centenas de estelas foram escavadas por Auguste Mariette (1857-1858) no cemitério norte, onde ele encontrou estelas pertencentes aos mesmos indivíduos das estelas do Museu Nacional como é o caso de Iunefer (inv. 627) e sua família. Tanto a estela do Museu Nacional como outra no Museu do Cairo estavam provavelmente em uma capela votiva no "Terraço do Grande Deus".

Outras capelas foram escavadas por Flinders Petrie (1902-1903) ao norte de Abidos e mais recentemente David O'Connor encontrou várias datadas do Médio Império até o reinado de Ramessés II no chamado "Portal do Templo".

Esta prática das estelas votivas e da peregrinação para Abidos manteve-se durante o Novo Império principalmente durante a XIX dinastia, quando são construídos os templos memoriais de Ramessés II, Séthi I e o Osireion. 
Embora mahat ou capelas memoriais raramente sejam mencionadas durante o Novo Império é possível que em muitos lugares da escarpa tenha existido locais de deposição de estelas ou ainda na parte externa do muro do recinto do templo de Thutmés III.

Estelas representando Osíris, datadas do Novo Império raramente se referem diretamente ao festival. Muitas estelas do Museu Nacional datadas da XIX e XX dinastias podem estar nesta categoria de estelas votivas abdianas, como as estelas de Huy filho de Pahu (inv. 653), Itu (inv.662), Seniresi (inv.659) e Huynefer (inv.667) que trazem na luneta a figura de Osíris e sua família divina, Ísis e Hórus hieracocéfalo ou simplesmente Osíris, como nas estelas de Siese (inv.673), Nebnufer (inv.663), Raia (inv.33), Wisy (inv.658), Hai (inv.665) entre outras, dedicadas a "Osíris Senhor de Abidos".

Durante o Terceiro Período Intermediário, particularmente na XXI e XXII dinastias, Abidos passa a ter uma forte ligação com o clero de Amun de Karnak que atuava institucionalmente no culto. Sob Sheshonq I e Osorkon I novas estelas e oferendas são feitas em honra a Osíris pelos profetas de Amun, e alguns são sepultados em Abidos como foi o caso do Sumo Sacerdote de Amun Iuput dentro do recinto sagrado do templo.

Durante o Período Ptolomaico Abidos continua sendo considerada como o local sagrado de Osíris, prestigiada pelas dinastias lágidas, embora neste período 
praticamente cada grande cidade egípcia possuísse um local considerado como sendo a "tumba" de Osíris fazendo com que Abidos perdesse muitos peregrinos. No Período Romano Abidos tem a sua importância bastante reduzida a julgar pelo relato de Estrabão.

Abidos de um passado grandioso, repleta de templos, cenotáfios, um vasto cemitério e inúmeros testemunhos de devoção a Osíris, que a fez comparável a Tebas viu-se reduzida a uma vila provincial onde eram sepultados os sacerdotes locais e os modestos habitantes.

\section{CONCLUSÃO}

As estelas egípcias ainda são estudadas e expostas nos museus segundo critérios que se concentram na forma, função, tipologia, evolução estrutural e datação.

Os estudos feitos nas estelas do Museu Nacional, provenientes de Abidos, mostram que é possível recriar o contexto arqueológico e os valores sociais presentes nestes objetos. A obtenção de informações dos próprios objetos associadas a uma bibliografia especializada e a comparação com outros monumentos em outros museus permite ultrapassar o limite da simples descrição e classificação.

As estelas do Museu Nacional tinham a função de comemorar a participação do ofertante nos rituais de Abidos representando o donatário e seus "convidados" 
perpetuamente nos rituais em honra a Osíris, demonstrando publicamente um nível de acesso ao domínio que antes era restrito a realeza. A instalação de uma capela votiva em um local sagrado era a garantia da participação perpétua nos rituais.

Ao contrário da peregrinação a Meca, a viagem dos devotos, vindos de todas as regiões do Egito até Abidos, não era um ato obrigatório, mas sim a manifestação da devoção pessoal e familiar dos egípcios.

Em Abidos este acesso parece ter sido concedido em sua totalidade a um indivíduo ou através de um intermediário de status elevado que poderia ou participar das cerimônias em nome de outro de status menor, ou de sua família ou simplesmente daqueles que não tinham condições de ir até Abidos. Como tal este ofertante é representado em destaque nas estelas. Embora considerados monumentos "privados", isto é, não pertencentes a realeza, esses monumentos existem no domínio público e refletem as mudanças sociais e políticas.

Estas estelas votivas, surgidas no Médio Império são artefatos religiosos indicativos do aumento da participação religiosa entre um grupo social anteriormente em silêncio no registro histórico.

O status social está incorporado nestes monumentos, pelo menos aquele escolhido pelos devotos para ser preservado por toda a eternidade. E a devoção destas 
pessoas ao seu deus ainda pode ser vista quase 4 mil anos depois no Museu Nacional do Rio de Janeiro.

\section{REFERÊNCIAS BIBLIOGRÁFICAS}

BRANCAGLION, Antonio, Jr. From Egypt To Brazil - an Egyptian Collection in Rio de Janeiro. In Egyptian Museum Collections around the World. Studies for the Centennial of the Egyptian Museum, Cairo. Cairo: American University in Cairo/Cairo Museum, pp. 155-62, 2002.

BUDGE, Sir Ernest Alfred Thompson Wallis. Hieroglyphic Texts from Egyptian Stelae, $\& C$., in the British Museum. Part 2. London: The Trustees of the British Museum, 1912.

CAMINOS, Ricardo Augusto; FISCHER, Henry G.. Ancient Egyptian Epigraphy and Palaeography: The Recording of Inscriptions and Scenes in Tombs and Temples. Archaeological Aspects of Epigraphy and Palaeography. New York: The Metropolitan Museum of Art, 1979.

EATON, Katherine J. The Festivals of Osiris and Sokar in the Month of Khoiak: The Evidence from Nineteenth Dynasty Royal Monuments at Abydos. Studien zur Altägyptischen Kultur, Bd. 35, pp. 75-101. 2006

GEUS, Francis [et al.] Mélanges offerts à Jean Vercoutter. Paris: Editions Recherche sur les Civilisations, 1985

GRAJETZKI, Wolfram. Court Officials of the Egyptian Middle Kingdom. London: Duckworth. 2009.

QUIRKE, Stephen. Titles and bureaux of Egypt 1850-1700 BC. London: Golden House Publications, 2004.

MARIETTE, Auguste. Catalogue général des monuments d'Abydos découverts pendant les fouilles de cette ville. Paris: Imprimerie Nationale, 1880.

O'CONNOR, David. Abydos. Egypr's First Pharaohs and the Cult of Osiris. London: Thames and Hudson, 2009. 
O'CONNOR, David. The "Cenotaphs" of the Middle Kingdom at Abydos in POSENERKRIÉGER, Paule [ed.]. Mélanges Gamal Eddin Mokhtar.II:161-178. Le Caire: IFAO, 1985.

RICHARDS, Janet. Society and Death in Ancient Egypt Mortuary Landscapes of the Middle Kingdom. Cambridge: Cambridge University Press, 2005.

SIMPSON, William Kelly. The Terrace of the Great God at Abydos: The offering chapels of dynasties 12 and 13. New Haven/Philadelphia: Yale University/University of Pennsylvania, 1974.

SMITHER, Paul. The Writing of Htp-di-nsw in the Middle and New Kingdoms. The Journal of Egyptian Archaeology, vol. 25 N.1, 1939: 34-37 